\title{
Serum HtrA1 is differentially regulated between early-onset and late-onset
}

\section{preeclampsia}

Sonia Soo Yee Teoh ${ }^{1,2, \#}$, Min Zhao ${ }^{3, \#}$, Yao Wang ${ }^{1,2}$, Qi Chen ${ }^{4,5}$ and Guiying Nie ${ }^{1,2, *}$

${ }^{1}$ Implantation and Placental Development Laboratory, Centre for Reproductive Health, Hudson Institute of Medical Research, Clayton, Victoria, Australia; ${ }^{2}$ Monash University, Clayton, Victoria, Australia; ${ }^{3}$ Wuxi Maternity and Children's Health Hospital, Nanjing Medical University, Jiangsu, China; ${ }^{4}$ The Hospital of Obstetrics and Gynaecology, Fudan University, China, ${ }^{5}$ Department of Obstetrics and Gynaecology, The University of Auckland, New Zealand

Running head: Serum levels of HtrA1 in different PE subtypes

\#These authors contributed equally to this work

*Corresponding author: Associate Professor Guiying Nie, Centre for Reproductive Health, Hudson Institute of Medical Research, Clayton, Victoria, Australia; Phone: +61-3-95944380; Fax: +61-3-95946125; e-mail: guiying.nie@hudson.org.au 


\section{Abstract}

\section{Introduction}

HtrA1 (high temperature requirement A1) is a serine protease of the HtrA family. We have previously shown that the placenta expresses the highest level of HtrA1 mRNA compared to other tissues in the human. Others have reported that placental HtrA1 is significantly upregulated in preeclampsia (PE), a pregnancy-specific multi-systemic disorder associated with new onset hypertension and proteinuria. However, it is unclear how serum HtrA1 changes in a normal pregnancy and whether it is altered in PE pregnancies.

\section{Methods}

A sandwich ELISA highly specific to human HtrA1 and suitable for serum detection was developed and thoroughly validated. This assay was then applied to serum samples from different stages of normal pregnancy, as well as early-onset ( $<34$ weeks) and late-onset $(>34$ weeks) PE pregnancies.

\section{Results}

Serum HtrA1 increased progressively with increasing gestation in normal pregnancies.

However, this trend was perturbed in women with PE. Compared to respective gestation-agematched normal pregnancies, HtrA1 serum levels were significantly increased in early-onset PE, but significantly reduced in late-onset PE.

\section{Discussion}

This is the first report to show a clear increase of HtrA1 in the maternal circulation during normal pregnancy, consistent with HtrA1 being highly expressed in the placenta. Importantly, this study identified that serum HtrA1 was altered differently in early-onset and late-onset PE 
pregnancies, highlighting the complex regulation of HtrA1 in the different subtypes. The significant increase of serum HtrA1 in early-onset PE suggests that it may be a potential biomarker for the diagnosis of early-onset PE at disease presentation.

\section{Keywords}

HtrA1; Serine protease; Preeclampsia; Pregnancy; Enzyme Linked Immunosorbent Assay 
1

2 Complicating 2-8\% of pregnancies, preeclampsia (PE) remains a leading cause of maternal and fetal deaths worldwide $[1,2]$, and is responsible for $14 \%$ of pregnancy related mortalities

4 [3]. PE is associated with the development of de novo hypertension (>140/90 $\mathrm{mm} \mathrm{Hg}$ ) and

5 proteinuria ( $>0.3 \mathrm{~g}$ per 24 hours) at or after 20 weeks pregnancy [4]. It is a syndrome with

6 major differences in clinical presentation, highlighting heterogeneity in the underlying

7 pathophysiology. Attempts have been made to classify PE into distinct subtypes, one of

8 which is to divide cases into early- and late-onset groups, according to the gestational age at

9 diagnosis or at delivery [5-7]. Early-onset PE occurs before 34 weeks of gestation, is often more severe, and frequently associated with intrauterine growth restriction (IUGR) and abnormal placentation. Late-onset PE, representing the majority of PE cases, occurs after 34 weeks of pregnancy $[8,9]$ and is less often associated with IUGR, but severe maternal complications can still occur $[10,11]$.

The high temperature requirement A (HtrA) proteases are a well conserved family of serine proteases found in organisms ranging from bacteria to mammals [12]. HtrAs exert important functions in protecting cells from stress conditions such as heat shock, oxidative stress, 
arthritic disorders $[21,22]$, cerebral autosomal recessive arteriopathy with subcortical infarcts and leukoencephalopathy [23], and age-related macular degeneration [24, 25]. We have previously reported that in the human, the placenta expresses the highest level of HtrA1 mRNA [26]. It is now known that placental HtrA1 expression increases from the first to the third trimester of pregnancy [27], is abnormally elevated in patients with PE [28, 29], and PE placentas have a four-fold increase in HtrA1 mRNA compared to controls [30]. These observations suggest that HtrA1 may contribute to the normal development of the placenta and to the pathogenesis of PE.

HtrA1 protein has also been reported to be elevated in sera of PE patients [31, 32]. One of these studies used a commercial enzyme-linked immunosorbent assay (ELISA) kit to determine serum HtrA1 [31]. However, the levels reported were very low, and the authors noted that the study was preliminary. Using the same kit, Inagaki et al [29] also detected low levels of HtrA1 in pregnant sera and found no difference between control and PE, although they showed that HtrA1 mRNA was significantly increased in PE placentas. We attempted to use the same ELISA kit, but in our hands it did not work properly for serum detection.

In this study, we developed and thoroughly validated a sandwich ELISA suitable for detecting human HtrA1 in serum. Using this ELISA, we determined serum levels of HtrA1 in normal and PE pregnancies, and discovered that HtrA1 concentrations were altered differently between early-onset and late-onset PE. Our data also suggested that serum HtrA1 might be a useful biomarker for the diagnosis of early-onset PE. 


\section{Materials and Methods}

\subsection{Ethics Statement}

This cross sectional study was approved by the Human Research Ethics Committee of Wuxi Maternity and Children's Hospital, Nanjing Medical University, China, and written informed consent was obtained from all participants. PE diagnosis was based on blood pressure elevation (systolic $\geq 140$ or diastolic $\geq 90 \mathrm{mmHg}$ ) and new-onset proteinuria based on dipstick grading of more than $1+(30 \mathrm{mg} / \mathrm{dL})$. Information on the women studied is shown in Table 1.

\subsection{Patient Selection}

Maternal sera were collected from healthy pregnant women at gestation weeks of 11-13 $(\mathrm{n}=12), 23-27(\mathrm{n}=14)$ and $33-40(\mathrm{n}=15)$, representing $1^{\text {st }}, 2^{\text {nd }}$ and $3^{\text {rd }}$ trimester respectively. Maternal sera were also collected from patients at the time of diagnosis of early-onset (28-34 wks, $\mathrm{n}=16$ ) and late-onset (>34 wks, n=19) PE and from gestation-age-matched normotensive controls (28-34 wks, $n=19 ;>34$ wks, $n=51)$. All samples were collected at Wuxi Maternity and Children's Health Hospital of Nanjing Medical University, China.

\subsection{Recombinant Human HtrA Proteins and Antibodies}

Full length human HtrA1, HtrA3 and HtrA4 proteins produced in insect cells were purchased from ProteaImmun GmbH (Berlin, Germany). Mature HtrA2 protein produced in E. coli was obtained from R\&D Systems (Minneapolis, MN, USA).

HtrA1 antibodies (a sheep polyclonal and a mouse monoclonal) were purchased from R\&D systems (Minneapolis, MN, USA). The HtrA2 antibody (goat polyclonal) was purchased from Santa Cruz Biotechnology (Santa Cruz, CA, USA), the HtrA4 antibody (rabbit 
polyclonal) was from Abcam (Cambridge, England, UK), and the HtrA3 antibody (mouse monoclonal) was produced as previously described [33].

\subsection{Western Blot}

Equal amounts (100 ng) of recombinant HtrA1, HtrA2, HtrA3 and HtrA4 proteins were analysed by standard Western blot (12\% reducing SDS-PAGE and PVDF membrane).

Primary antibodies were incubated overnight at $4{ }^{\circ} \mathrm{C}$ and blots were probed with appropriate horseradish peroxidase (HRP) secondary conjugates for $1 \mathrm{~h}$ at room temperature. Proteins were visualised by enhanced chemiluminescence (ECL) using Pierce ECL Western Blotting Substrate (Thermo Fisher Scientific, Rockford, IL, USA), and images were taken with Gel Doc (BioRad, Hercules, CA, USA).

\subsection{HtrA1 sandwich ELISA}

Sandwich ELISAs were performed in half-area high binding 96-well microplates (Corning, NY, USA). Plates were coated overnight at $4{ }^{\circ} \mathrm{C}$ with the sheep polyclonal HtrA1 antibody at $1 \mu \mathrm{g} / \mathrm{ml}$ in carbonate/bicarbonate buffer, $\mathrm{pH}$ 9.6. The plates were washed three times with PBS containing $0.5 \%(\mathrm{v} / \mathrm{v})$ Tween (PBST), and non-specific binding was blocked with $1 \%$ (w/v) BSA (Sigma-Aldrich, St. Louis, MO, USA) for $75 \mathrm{~min}$ at room temperature on a plate shaker. Plates were then washed twice with PBST, and incubated (50 $\mu \mathrm{l} /$ well) with antigens for $2 \mathrm{~h}$ at room temperature. Following this, plates were incubated with mouse monoclonal anti-HtrA1 antibody $(0.5 \mu \mathrm{g} / \mathrm{ml}$ in PBST) for $1 \mathrm{~h}$, a biotinylated horse anti-mouse IgG secondary antibody (150 $\mu \mathrm{g} / \mathrm{ml}$ in PBST; Vector Laboratories, Burlingame, CA, USA) for 40 min, and streptavidin-HRP (Dako, Carpinteria, CA, USA, diluted 1:1000 in PBST) for 30 min. Between each of these incubations, plates were washed three times with PBST with 1 min soaking at each wash. Plates were then incubated with $50 \mu \mathrm{l} /$ well of 1-Step Ultra TMB (Thermo Fisher Scientific, Rockford, IL, USA) in the dark for 10 min. To stop the reaction, 
$25 \mu \mathrm{l}$ of $1 \mathrm{M} \mathrm{H}_{2} \mathrm{SO}_{4}$ were added to each well, and absorbance at $450 \mathrm{~nm}$ was determined (Wallac EnVision Multilabel Plate reader, Perkin Elmer, Waltham, MA, USA). All wash steps were performed using an automated plate washer (ELx50 Washer, BioTek, Winooski, VT, USA).

Recombinant HtrA1 was used as the HtrA1 standard by spiking known concentrations in PBST buffer with or without 5\% fetal calf serum (FCS) or 10\% HtrA1-negative human serum (HS) as indicated. Quality control (QC) samples were prepared by spiking in PBST different amounts of a human serum sample highly positive for HtrA1. All human serum samples were assayed after 1/10 dilution in PBST buffer.

\subsection{Statistical analysis}

Data are expressed as Mean \pm SEM. Statistical analysis was performed using ordinary one-way ANOVA (for $>2$ groups) or unpaired t-test (for 2 groups) on log-transformed data using GraphPad PRISM version 6.00 (GraphPad Software, San Diego, CA). P<0.05 was taken as significant. Receiver-operating curve (ROC) was also generated using PRISM.

\section{Results}

3.1. Specificity of HtrA1 antibodies and the sandwich ELISA. Sandwich ELISAs require two distinct antibodies that bind to different sites on the antigen. A sheep polyclonal and a mouse monoclonal HtrA1 antibody were first evaluated for their specificity. Equal amounts of recombinant HtrA1, HtrA2, HtrA3 and HtrA4 were analyzed by Western blot. Both antibodies detected HtrA1 very specifically and did not recognize any other members of the HtrA family (Fig. 1, top panel). All HtrAs were confirmed to be intact by probing identical blots with antibodies specific to HtrA2, HtrA3 and HtrA4, respectively (Fig. 1, bottom panel). 
Sandwich ELISAs require one antibody to capture the antigen from the analyte and another antibody to detect the captured antigen. We tested the two possible combinations with the two HtrA1 antibodies in sandwich ELISA on recombinant HtrA1. The best combination was to capture with the sheep polyclonal antibody and to detect using the mouse monoclonal antibody (data not shown). The specificity of this HtrA1 sandwich ELISA was then validated by analyzing $10 \mathrm{ng}$ of recombinant HtrA1, HtrA2, HtrA3 and HtrA4 (Fig. 2A), and only HtrA1 was detected.

3.3. Optimisation of HtrA1 sandwich ELISA for serum detection. We next tested whether the serum matrix would affect the assay. Two-fold serial dilutions of recombinant HtrA1 were prepared in standard diluent (PBST buffer) with and without different concentrations of an HtrA1-negative human serum (HS). In general, the signal was inversely proportional to the amount of serum in the assay, and comparison of matrix effect on the assay between no serum and 10\% HS is shown in Figure 2B. We also tested foetal calf serum (FCS), and found that the HtrA1 standards prepared in 5\% FCS were very similar to that prepared in $10 \% \mathrm{HS}$ (Fig. 2B). This highlighted the need to include serum in the HtrA1 standard to match the matrix of the serum samples being assayed. This also suggests that FCS, which is widely available, can be added to the HtrA1 standard to correct for matrix effect when assaying human serum samples.

3.4. HtrA1 ELISA working range, intra- and inter-assay variations. The accuracy of the HtrA1 ELISA was first determined by comparing the back-calculated concentrations of the standards in $10 \%$ HS to the nominal input concentrations. The average recovery between 15.6 to $250 \mathrm{ng} / \mathrm{ml}$ of HtrA1 was within $10 \%$ of the nominal concentrations, indicating high assay accuracy (Table 2A). The assay was also very reproducible within this range, evidenced by 
$<10 \%$ intra- and inter-assay variations (Table 2A). The limit of quantification was $15.6 \mathrm{ng} / \mathrm{ml}$, as a high inter-assay variation was seen below this concentration (Table 2A).

The assay reproducibility was further tested on quality control (QC) serum samples, which were prepared by diluting a serum sample of high HtrA1 concentration in HS. These QC samples were then diluted 1:10 in PBST (final 10\% serum concentration) and assayed multiple times. The intra-assay variation ranged between $6.1 \%-8.7 \%$, and the inter-assay variation was between $13.6 \%-17.5 \%$ (Table $2 \mathrm{~B}$ ), confirming assay reproducibility with serum samples.

\subsection{Serum levels of HtrA1 in normotensive pregnancies. Using the established HtrA1}

ELISA, we assayed serum samples collected from different stages of normal pregnancy. Serum levels of HtrA1 increased significantly from one trimester to the next (Fig. 3A). When the same data were analyzed by weeks of gestation, serum HtrA1 levels showed a clear progressive increase with gestation (Fig. 3B).

\subsection{HtrA1 is differentially regulated in early-onset vs. late-onset PE. We next assayed} serum samples collected from women who developed early-onset PE $(n=16)$ or late-onset PE $(n=19)$, and compared to their respective gestation-age-matched control pregnancies $(<34$ weeks, $n=19 ;>34$ weeks, $n=51$ ). Serum levels of HtrA1 were significantly higher in women with early-onset PE compared to their respective controls ( $\mathrm{P}=0.0004$, Fig. 4A). However, this difference was reversed in late-onset PE, where serum HtrA1 was lower compared to the respective control pregnancies $(\mathrm{P}=0.0277$, Fig. 4B). Consistent with data shown in Fig. 3, serum levels of HtrA1 in control samples of $>34$ weeks gestation were much higher than those of $<34$ weeks (Fig. 4). This data suggests that serum HtrA1 is perturbed in women who develop PE, but this perturbation is different in early-onset vs and late-onset PE women. 

significantly increased in early-onset PE compared to the gestation-age-matched controls, we next determined if this increase could be used to diagnose early-onset PE. A receiveroperating curve (ROC) was generated using the data presented in Figure 4A. The AUC was 0.8372 with $\mathrm{P}=0.0007$ (Fig. 5). At $80.80 \mathrm{ng} / \mathrm{ml}$ of $\mathrm{HtrA} 1$, the sensitivity was $81.25 \%$ and specificity $78.95 \%$. If the cut-off concentration was set at $55 \mathrm{ng} / \mathrm{ml}$ the sensitivity would increase to $93.75 \%$, but the sensitivity would only be $47.37 \%$.

\section{Discussion}

In this study, we established a reliable and accurate ELISA that is specific to HtrA1 and suitable for serum detection; its intra- and inter-assay variations were $<10 \%$ and its working range was between $15.6-250 \mathrm{ng} / \mathrm{ml}$. It is important to note that HtrA1-negative serum

As HtrA1 is a secreted protein [34], placental secretion of HtrA1 is expected to be present in the circulation of pregnant women. While previous studies reported the detection of HtrA1 in 
kit, which in our test did not work with serum samples. Our newly established and thoroughly validated ELISA detected average levels of 30, 80 and $200 \mathrm{ng} / \mathrm{ml}$ of HtrA1 in sera from $1^{\text {st }}$, $2^{\text {nd }}$ and $3^{\text {rd }}$ trimesters respectively. These data agree with previous studies using immunohistochemistry and in-situ hybridization, which show that placental HtrA1 mRNA as well as protein is up-regulated from the $1^{\text {st }}$ to the $3^{\text {rd }}$ trimester $[27,36]$.

Previous studies reported significant up-regulation of HtrA1 mRNA in PE placentas, but how serum HtrA1 changes in PE pregnancies remains unclear. Our study demonstrated that serum HtrA1 was significantly increased in early-onset but not in late-onset PE compared to respective gestation age-matched controls, suggesting an elevation of HtrA1 in the maternal circulation of early-onset PE pregnancies. The ROC curve generated with early-onset PE samples indicated a potential utility of HtrA1 as a marker of early-onset PE. Although it is unlikely that any single biomarker alone would effectively detect a disorder as heterogenous as $\mathrm{PE}$, it is possible that monitoring serum HtrA1 in conjunction with other biomarkers, such as soluble endoglin, soluble fms-like tyrosine kinase and placental growth factor [37-41], may improve the diagnosis of early-onset PE.

The functional importance of HtrA1 in placentation or PE is yet to be elucidated. However, HtrAs are known to function in protecting cells from stress by degrading unfolded, misfolded or otherwise aberrant proteins, and they may also serve as chaperones to protect protein structure [13, 42]. Recently, a study investigating stress-signalling pathways including unfolded protein response, heat-shock proteins and MAPK stress pathways, suggests that placental stress may contribute to the pathophysiology of early-onset PE, but not late-onset PE [43]. It is thus possible that an increase in serum HtrA1 may reflect placental stress in early-onset PE. 

human serum. Using this ELISA, we found that serum levels of HtrA1 increased as gestation progresses in normotensive pregnancies, and that HtrA1 serum levels were differentially regulated between early- and late-onset PE. HtrA1 may be involved in the development of early-onset PE, and assessing HtrA1 serum levels may improve the diagnosis of early-onset PE.

\section{Acknowledgements}

This work was supported by the National Health and Medical Research Council of Australia Fellowship \#1041835 (to GN), the Bill and Melinda Gates Foundation, and the Victorian Government Operational Infrastructure Support Program.

Author Contributions

GN QC conceived and designed the experiments; ST YW MZ QC performed the experiments; ST QC GN analyzed the data; MZ QC obtained and provided serum samples; GN QC contributed reagents/materials/analysis tools; ST GN QC wrote the paper.

\section{References}

1. Duley, L., The global impact of pre-eclampsia and eclampsia. Semin Perinatol, 2009. 33(3): p. 130-7.

2. Than, N.G., et al., Prediction of preeclampsia - a workshop report. Placenta, 2008. 29 Suppl A: p. S83-5.

3. Osungbade, K.O. and O.K. Ige, Public health perspectives of preeclampsia in developing countries: implication for health system strengthening. J Pregnancy, 2011. 2011: p. 481095. 
4. Milne, F., et al., The pre-eclampsia community guideline (PRECOG): how to screen for and detect onset of pre-eclampsia in the community. BMJ, 2005. 330(7491): p. 576-80.

5. Myatt, L., et al., Strategy for standardization of preeclampsia research study design. Hypertension, 2014. 63(6): p. 1293-301.

6. Staff, A.C., et al., Redefining preeclampsia using placenta-derived biomarkers. Hypertension, 2013. 61(5): p. 932-42.

7. von Dadelszen, P., L.A. Magee, and J.M. Roberts, Subclassification of preeclampsia. Hypertens Pregnancy, 2003. 22(2): p. 143-8.

8. Klungsoyr, K., et al., Secular trends in the epidemiology of pre-eclampsia throughout 40 years in Norway: prevalence, risk factors and perinatal survival. Paediatr Perinat Epidemiol, 2012. 26(3): p. 190-8.

9. Sibai, B.M., Management of late preterm and early-term pregnancies complicated by mild gestational hypertension/pre-eclampsia. Semin Perinatol, 2011. 35(5): p. 292-6.

10. Douglas, K.A. and C.W. Redman, Eclampsia in the United Kingdom. BMJ, 1994. 309(6966): p. 1395-400.

11. Sibai, B.M., et al., Maternal morbidity and mortality in 442 pregnancies with hemolysis, elevated liver enzymes, and low platelets (HELLP syndrome). Am J Obstet Gynecol, 1993. 169(4): p. 1000-6.

12. Clausen, T., et al., HTRA proteases: regulated proteolysis in protein quality control. Nat Rev Mol Cell Biol, 2011. 12(3): p. 152-62.

13. Clausen, T., C. Southan, and M. Ehrmann, The HtrA family of proteases: implications for protein composition and cell fate. Mol Cell, 2002. 10(3): p. 443-55.

14. Chien, J., et al., HtrA serine proteases as potential therapeutic targets in cancer. Curr Cancer Drug Targets, 2009. 9(4): p. 451-68.

15. Wang, L.J., et al., High-temperature requirement protein A4 (HtrA4) suppresses the fusogenic activity of syncytin-1 and promotes trophoblast invasion. Mol Cell Biol, 2012. 32(18): p. 3707-17.

16. Eigenbrot, C., et al., Structural and functional analysis of HtrAl and its subdomains. Structure, 2012. 20(6): p. 1040-50.

17. Zumbrunn, J. and B. Trueb, Primary structure of a putative serine protease specific for IGF-binding proteins. FEBS Lett, 1996. 398(2-3): p. 187-92. 
18. Chien, J., et al., Serine protease HtrAl modulates chemotherapy-induced cytotoxicity. J Clin Invest, 2006. 116(7): p. 1994-2004.

19. Chien, J., et al., A candidate tumor suppressor HtrAl is downregulated in ovarian cancer. Oncogene, 2004. 23(8): p. 1636-44.

20. He, X., et al., Downregulation of HtrAl promotes resistance to anoikis and peritoneal dissemination of ovarian cancer cells. Cancer Res, 2010. 70(8): p. 3109-18.

21. Grau, S., et al., The role of human HtrAl in arthritic disease. J Biol Chem, 2006. 281(10): p. 6124-9.

22. Tsuchiya, A., et al., Expression of mouse HtrAl serine protease in normal bone and cartilage and its upregulation in joint cartilage damaged by experimental arthritis. Bone, 2005. 37(3): p. 323-36.

23. Hara, K., et al., Association of HTRA1 mutations and familial ischemic cerebral small-vessel disease. N Engl J Med, 2009. 360(17): p. 1729-39.

24. Dewan, A., et al., HTRA1 promoter polymorphism in wet age-related macular degeneration. Science, 2006. 314(5801): p. 989-92.

25. Yang, Z., et al., A variant of the HTRA1 gene increases susceptibility to age-related macular degeneration. Science, 2006. 314(5801): p. 992-3.

26. Nie, G.Y., et al., Identification and cloning of two isoforms of human hightemperature requirement factor A3 (HtrA3), characterization of its genomic structure and comparison of its tissue distribution with HtrAl and HtrA2. Biochem J, 2003. 371(Pt 1): p. 39-48.

27. De Luca, A., et al., The serine protease HtrAl is upregulated in the human placenta during pregnancy. J Histochem Cytochem, 2004. 52(7): p. 885-92.

28. Ajayi, F., et al., Elevated expression of serine protease HtrAl in preeclampsia and its role in trophoblast cell migration and invasion. Am J Obstet Gynecol, 2008. 199(5): p. 557 e1-10.

29. Inagaki, A., et al., Upregulation of HtrA4 in the placentas of patients with severe preeclampsia. Placenta, 2012. 33(11): p. 919-26.

30. Kang, J.H., et al., Preeclampsia leads to dysregulation of various signaling pathways in placenta. J Hypertens, 2011. 29(5): p. 928-36.

31. Marzioni, D., et al., Alterations of maternal plasma HTRA1 level in preeclampsia complicated by IUGR. Placenta, 2012. 33(12): p. 1036-8. 
32. Zong, L., Wang, L., Huang, P., Shao W., Song, Y., Gou, W., High temperature requirement A1 in placental tissues and serum from pre-eclamptic pregnancies with or without fetal growth restriction. Archives of Medical Science, 2012. 9(4): p. 690696.

33. Dynon, K., et al., HtrA3 as an early marker for preeclampsia: specific monoclonal antibodies and sensitive high-throughput assays for serum screening. PLoS One, 2012. 7(9): p. e45956.

34. Hu, S.I., et al., Human HtrA, an evolutionarily conserved serine protease identified as a differentially expressed gene product in osteoarthritic cartilage. J Biol Chem, 1998. 273(51): p. 34406-12.

35. Zong, L., et al., Changes in the level of serum high-temperature requirement A1 (HtrA1) during pregnancy and its relationship to preeclampsia. Hypertens Pregnancy, 2012. 31(4): p. 389-97.

36. Marzioni, D., et al., Expression pattern alterations of the serine protease HtrAl in normal human placental tissues and in gestational trophoblastic diseases. Histol Histopathol, 2009. 24(10): p. 1213-22.

37. Lee, E.S., et al., The levels of circulating vascular endothelial growth factor and soluble Flt-1 in pregnancies complicated by preeclampsia. J Korean Med Sci, 2007. 22(1): p. 94-8.

38. Levine, R.J., et al., Soluble endoglin and other circulating antiangiogenic factors in preeclampsia. N Engl J Med, 2006. 355(10): p. 992-1005.

39. McElrath, T.F., et al., Longitudinal evaluation of predictive value for preeclampsia of circulating angiogenic factors through pregnancy. Am J Obstet Gynecol, 2012. 207(5): p. 407 e1-7.

40. Moore Simas, T.A., et al., Angiogenic factors for the prediction of preeclampsia in high-risk women. Am J Obstet Gynecol, 2007. 197(3): p. 244 e1-8.

41. Venkatesha, S., et al., Soluble endoglin contributes to the pathogenesis of preeclampsia. Nat Med, 2006. 12(6): p. 642-9.

42. Skorko-Glonek, J., et al., HtrA protease family as therapeutic targets. Curr Pharm Des, 2013. 19(6): p. 977-1009.

43. Yung, H.W., et al., Differential activation of placental unfolded protein response pathways implies heterogeneity in causation of early-and late-onset pre-eclampsia. $\mathrm{J}$ Pathol, 2014. 234(2): p. 262-76. 


\section{Figure Legends}

Fig.1. Western blot analysis to confirm HtrA1 antibody specificity. (A) Equal amounts (100 ng each) of recombinant human HtrA proteins HtrA1 (A1), HtrA2 (A2), HtrA3 (A3) and HtrA4 (A4) were analyzed by Western blot with two HtrA1 antibodies, one sheep polyclonal and one mouse monoclonal. Both antibodies are specific to HtrA1. (B) Identical blots were also probed with antibodies against HtrA2, HtrA3 and HtrA4, respectively.

Fig. 2. Confirmation of HtrA1 ELISA specificity and effect of serum matrix. (A) Equal amounts (10 ng) of recombinant HtrA proteins were assayed by the HtrA1 ELISA. It specifically detected HtrA1. (B) Standard curves were constructed with recombinant HtrA1 serially diluted in PBS-T buffer with and without 5\% fetal calf serum (FCS) or 10\% HtrA1negative human serum (HS). Serum matrix markedly reduced signal intensity and changed the characteristics of the standard. Standard curves with 5\% FCS and 10\% HS were similar.

Fig. 3. Maternal serum HtrA1 concentration increases with gestation age. Serum levels of HtrA1 were determined by ELISA, and the relationship between HtrA1 concentration and gestation age is presented. (A) Gestation in three trimesters. Values are mean \pm SEM. $1^{\text {st }}$, $\mathrm{n}=12 ; 2^{\mathrm{nd}} \mathrm{n}=13 ; 3^{\text {rd }}, \mathrm{n}=17$. ** $\mathrm{P}=0.0017 ; * * * \mathrm{P}<0.0001$. (B) Gestation in weeks, $\mathrm{n}=42$. 
Fig. 4. Serum concentrations of HtrA1 are altered differently in early-onset vs late-onset PE. Serum HtrA1 concentrations from a cohort of pregnant women who developed earlyonset or late-onset PE were compared to their respective gestation-age-matched controls. Values are mean + SEM. (A) Early-onset ( $<34$ wks) PE. Control, n=19, PE, n=16. (B) Lateonset (>34 wks) PE. Control, $\mathrm{n}=51, \mathrm{PE}, \mathrm{n}=19 . * \mathrm{P}=0.0139 ; * * * \mathrm{P}=0.0006$.

Fig. 5. Receiver-operating characteristic (ROC) curves for early-onset PE. ROC curves were constructed using the data presented in Fig. 4(A) for early-onset PE $(n=16)$ and gestation-age-matched controls $(n=19)$. AUC was 0.8372 with $95 \%$ confidence interval of $0.7058-0.9685, \mathrm{P}=0.0007$. 


\begin{tabular}{|c|c|c|c|c|}
\hline & \multicolumn{2}{|c|}{ Early-Onset (28-34 wks) } & \multicolumn{2}{|c|}{ Late-Onset (>34 wks) } \\
\hline & $\begin{array}{c}\text { Control } \\
(n=19)\end{array}$ & PE $(n=16)$ & $\begin{array}{c}\text { Control } \\
(n=51)\end{array}$ & PE $(n=19)$ \\
\hline Maternal age (years) & $26.6( \pm 3.6)$ & $28.9( \pm 5.4)$ & $26( \pm 3.7)$ & $27.5( \pm 5.3)$ \\
\hline $\begin{array}{l}\text { Gestation week when } \\
\text { PE was diagnosed }\end{array}$ & NA & $30( \pm 3)$ & NA & $36( \pm 1)$ \\
\hline Gestation week at delivery & $39( \pm 1)$ & $34( \pm 1)$ & $39( \pm 1.6)$ & $37( \pm 1)$ \\
\hline $\begin{array}{l}\text { Systolic blood pressure } \\
(\mathrm{mmHg})\end{array}$ & $117( \pm 12)$ & $159( \pm 12)^{* * *}$ & $123( \pm 9)$ & $156( \pm 15)^{* * *}$ \\
\hline $\begin{array}{l}\text { Diastolic blood pressure } \\
\text { (mmHg) }\end{array}$ & $72( \pm 8)$ & $112( \pm 14)^{* * * *}$ & $78( \pm 7)$ & $102( \pm 12)^{* * *}$ \\
\hline Fetal birth weight (g) & $3312( \pm 383)$ & $1658 \underset{* * *}{( \pm 716)}$ & $3166( \pm 504)$ & $2668 \underset{* * 659)}{( \pm 659}$ \\
\hline Proteinuria & Negative & $>1+$ & Negative & $>1+$ \\
\hline
\end{tabular}

** $\mathrm{p}<0.01$, *** $\mathrm{p}<0.001$; Proteinuria dipstick grading: $1+=30 \mathrm{mg} / \mathrm{dL}$

Table 1. Preeclampsia and control subjects 


\begin{tabular}{|c|c|c|c|c|}
\hline $\begin{array}{c}\text { Nominal HtrA1 } \\
\text { concentration } \\
(\mathbf{n g} / \mathbf{m l})\end{array}$ & $\begin{array}{c}\text { Mean } \\
\text { Concentration } \\
\text { by ELISA } \\
(\mathbf{n g} / \mathbf{m l})\end{array}$ & $\begin{array}{c}\text { Mean \% } \\
\text { Recovery }\end{array}$ & $\begin{array}{c}\text { Intra-assay } \\
\mathbf{\%} \mathbf{C V}\end{array}$ & $\begin{array}{c}\text { Inter-assay } \\
\text { \% CV }\end{array}$ \\
\hline $\mathbf{2 5 0}$ & 250.17 & 99.56 & 9.93 & 3.82 \\
\hline $\mathbf{1 2 5}$ & 125.01 & 95.08 & 1.27 & 1.30 \\
\hline $\mathbf{6 2 . 5}$ & 62.44 & 99.89 & 0.86 & 1.86 \\
\hline $\mathbf{3 1 . 3}$ & 31.29 & 100.14 & 3.05 & 6.52 \\
\hline $\mathbf{1 5 . 6}$ & 15.69 & 100.49 & 5.06 & 9.18 \\
\hline $\mathbf{7 . 8}$ & 6.13 & 83.53 & 6.00 & 55.34 \\
\hline $\mathbf{3 . 9}$ & 1.93 & 50.00 & 87.19 & 110.40 \\
\hline
\end{tabular}

B

\begin{tabular}{ccc}
\hline QC & Intra-assay \% CV & Inter-assay \% CV \\
\hline High & $7.2 \%$ & $13.6 \%$ \\
Medium & $8.7 \%$ & $14.5 \%$ \\
Low & $6.1 \%$ & $17.5 \%$ \\
Average \% CV & $7.3 \%$ & $15.2 \%$ \\
\hline
\end{tabular}

Table 2 - Accuracy and precision of HtrA1 ELISA on HtrA1 standard (A) and QCs (B).

(A) Concentrations of HtrA1 standard diluted in 10\% HtrA1-negative human serum were back calculated from the HtrA1 standard curves and the mean percentage of recovery, intraand inter-assay variations are shown. (B) Concentration of HtrA1 in 3 quality control (QC) serum samples representing high, medium and low concentrations were determined by the HtrA1 ELISA and the intra-and inter-assay variations are shown. The intra-assay variation was calculated from one assay of six replicates, and inter-assay variation calculated from 19 independent assays. 

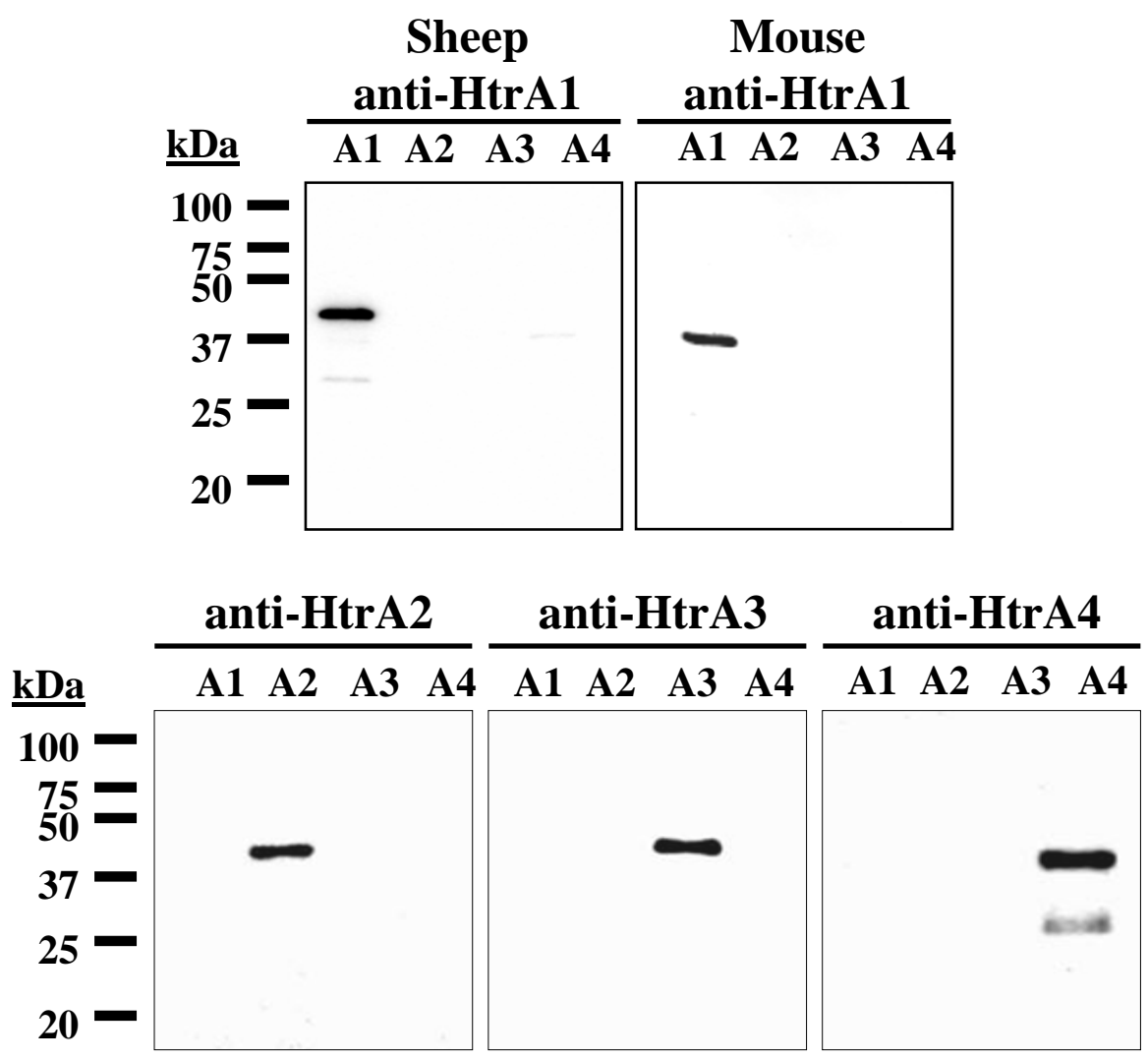
A

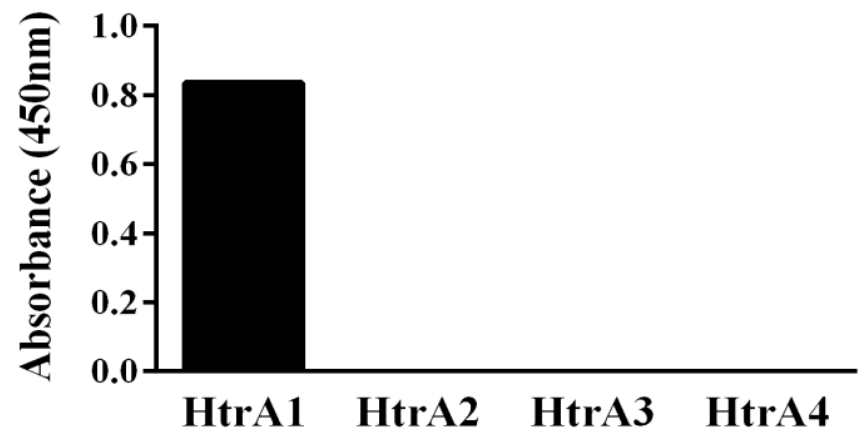

B

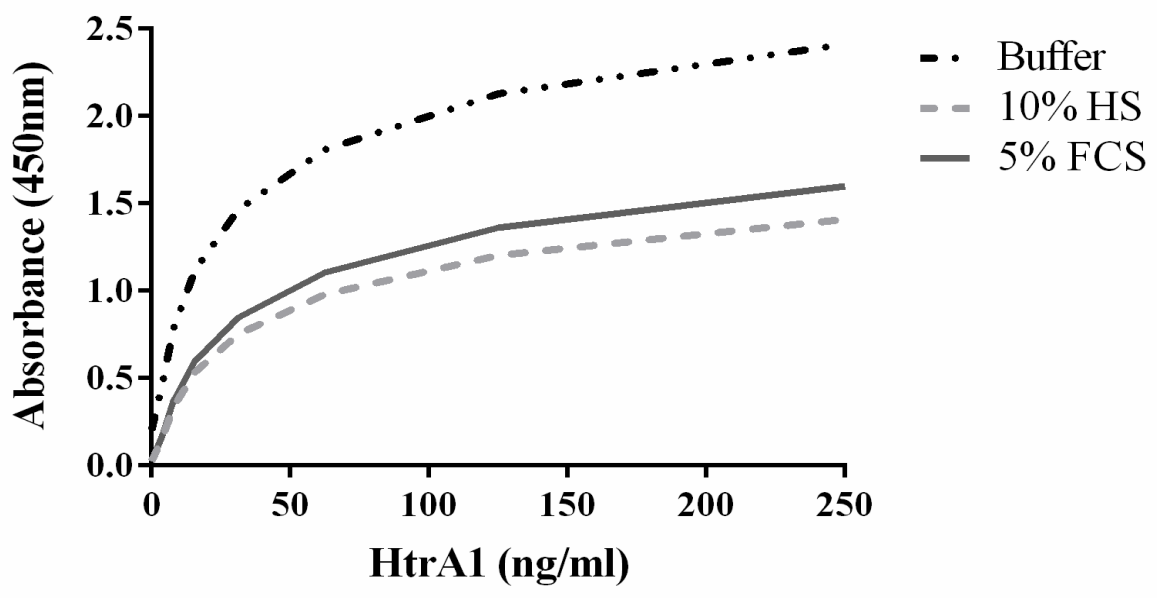


A

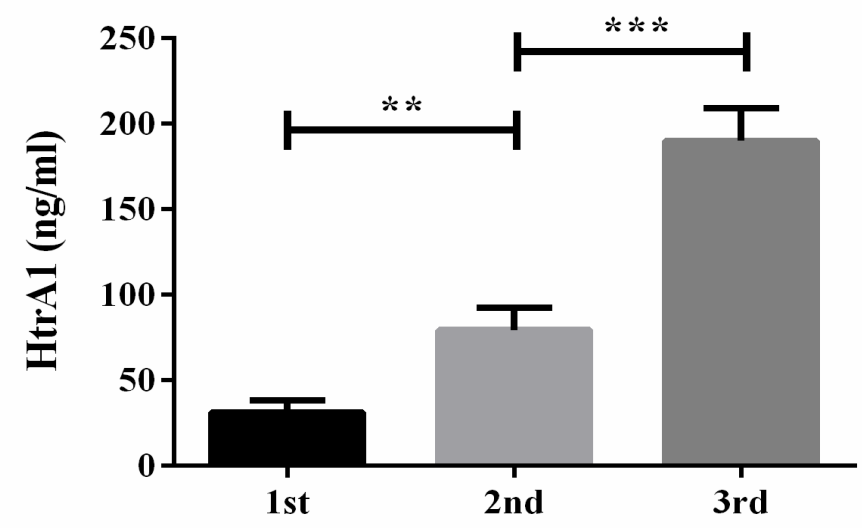

Trimester

B

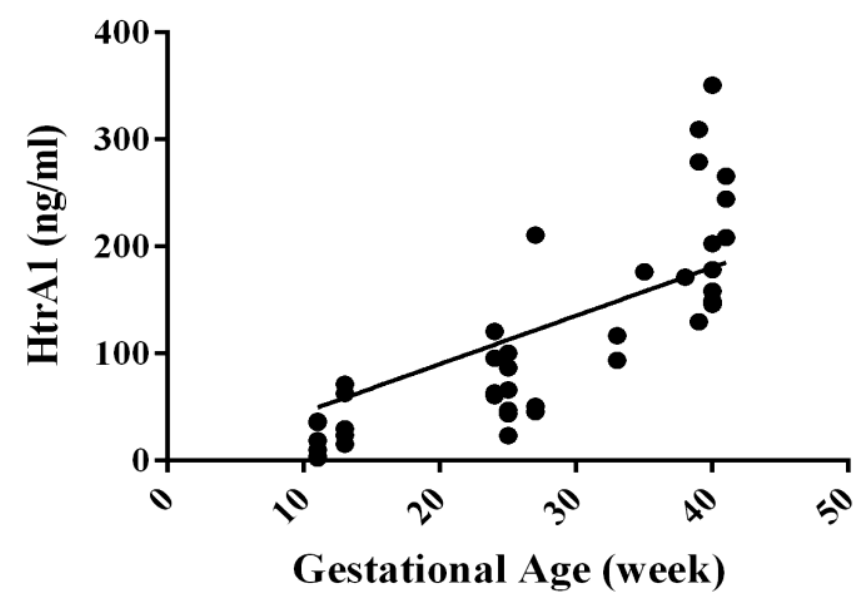

Fig 3 
A

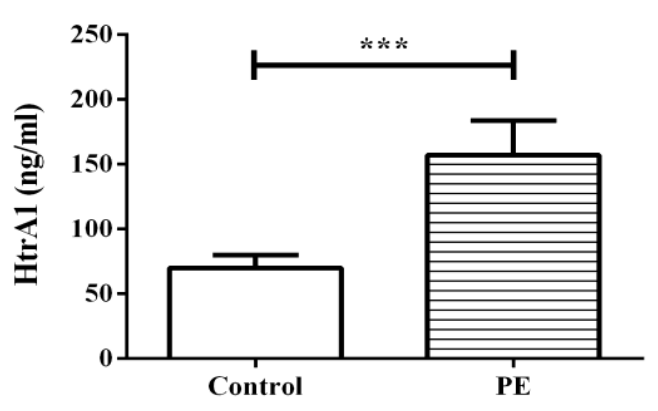

Early onset ( $<34$ wks)
B

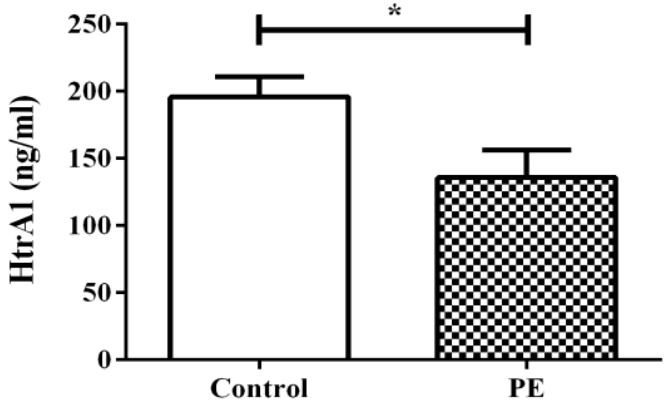

Late onset ( $>34$ w ks) 


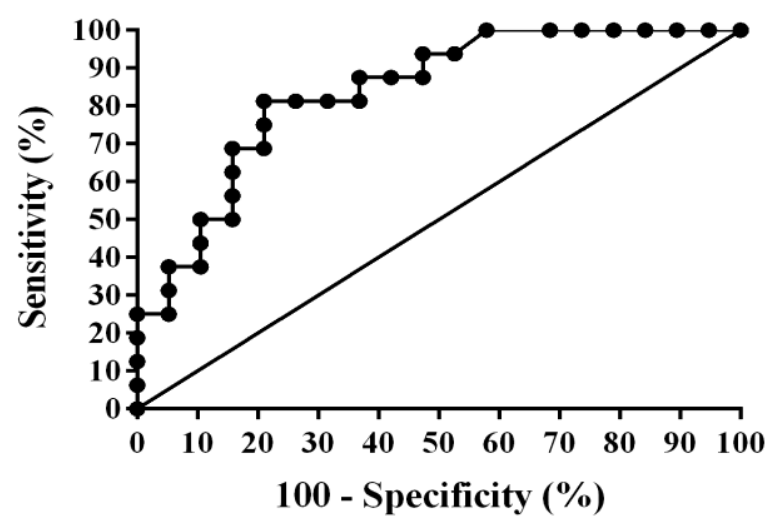

Fig 5 